\title{
Global warming threatens human thermoregulation and survival
}

\author{
Rexford S. Ahima \\ Division of Endocrinology, Diabetes and Metabolism, Department of Medicine, Johns Hopkins University School of Medicine, Baltimore, Maryland, USA.
}

$\mathbf{T}$ here is overwhelming evidence showing that human activities have contributed to global warming over the past century. Global warming has a severe impact on food and water supplies, housing and other infrastructure, health, and economic activities. The human body has thermoregulatory mechanisms that adapt to ambient temperature and maintain normal core body temperature for physiological functions. This JCI Viewpoint article discusses how extreme temperatures driven by global warming disrupt normal thermoregulation and imperil human health and survival.

\section{The Earth's greenhouse}

The term "global warming" denotes an aspect of climate change characterized by a rapid increase in the Earth's average surface temperature over the past century due mainly to the burning of fossil fuels that increase greenhouse gases (1). A naturally occurring greenhouse warming is primarily exerted by water vapor, and this plays a crucial role in keeping the Earth's surface temperature at a habitable $\sim 15^{\circ} \mathrm{C}\left(59^{\circ} \mathrm{F}\right)$ for humans and other species. Alarmingly, human activities, especially the burning of fossil fuels, have disrupted the Earth's natural greenhouse $(1,2)$. The level of atmospheric carbon dioxide has increased by more than a third since the industrial revolution began in 1750 (3). Methane, a potent greenhouse gas, is produced from decomposition of landfills, agricultural waste, and ruminant animals. Nitrous oxide is produced from fertilizers and burning of fossil fuel and vegetation. Excessive levels of carbon dioxide, methane, and nitrous oxide increase the greenhouse effect, trapping heat and causing the Earth's surface temperature to rise. As temperature increases, more water vapor evaporates from the oceans and other water sources into the atmosphere, causing temperature to increase further. The Earth's surface temperature has increased by $0.6^{\circ} \mathrm{C}-0.9^{\circ} \mathrm{C}$ from 1905 to 2005 , and climate models predict a further increase of approximately $2^{\circ} \mathrm{C}-6^{\circ} \mathrm{C}$ by the end of the 21 st century, if we continue burning more fossil fuels and accumulating greenhouse gases in Earth's atmosphere $(1,2)$.

\section{Human temperature regulation} Humans are "endothermic homeotherms"; i.e., we generate our own body heat and have the capacity to regulate body temperature (4). Body temperature is influenced by the environment, internal mechanisms (homeostasis), and behavioral adaptation (e.g., clothing, shelter, cooling and heating systems). Body temperature has two components: central (core) and peripheral (shell) (4). The core temperature, average $37^{\circ} \mathrm{C}$, is tightly controlled within a range of $33.2^{\circ} \mathrm{C}-38.2^{\circ} \mathrm{C}$ that ensures optimal physiological function. The core temperature fluctuates daily (i.e., circadian), monthly (e.g., during the menstrual cycle), and with aging. The hypothalamus is the coordinating center for body temperature regulation. A stable core temperature is achieved through homeostatic thermoregulatory mechanisms linking cold and warm receptors in the skin and brain to heat production from muscle and other organs.

The peripheral (shell) temperature, measured in the skin, hands, and feet, is approximately $4^{\circ} \mathrm{C}$ lower than core temperature; hence the normal direction of heat transfer is from the body to the environment. In a warm environment, heat loss occurs from skin vasodilation and sweating. During cold exposure, the skin blood flow is decreased through vasocon-

Conflict of interest: The author has declared that no conflict of interest exists.

Copyright: @ 2020, American Society for Clinical Investigation.

Reference information: / Clin Invest. 2020;130(2):559-561. https://doi.org/10.1172/JCI135006

striction, leading to a decrease in peripheral temperature and preservation of core temperature. Extreme deviations from the normal core temperature, i.e., a dip below $27^{\circ} \mathrm{C}$ (hypothermia) or an increase above $42^{\circ} \mathrm{C}$ (hyperthermia) can be fatal. As discussed in the next section, extreme heat spurred by global warming poses an existential threat to human populations.

\section{It's getting hotter and hotter}

As the Earth's climate warms, hotter days and nights and heat waves are becoming more frequent and intense $(1,2,5)$. Global warming is pushing the climate temperature curve toward the extreme range (5). Since the 1960s, the number of heat waves, defined as 2 or more consecutive days where temperatures exceeded historical summer (July and August) temperatures, has tripled in several US cities (6). The duration of heat waves has also increased (6). Globally, as the Arctic warms faster than the rest of the Northern Hemisphere, this will decrease the temperature gradient from the Arctic to the subtropics and tropics, disrupt the normal jet stream, and drive heat waves, droughts, wildfires, and floods $(1,2)$.

Large urban areas are usually warmer than surrounding rural areas because of loss of vegetation, more pavement and buildings that absorb the sun's energy, reduced airflow in alleys, and heat generated by vehicles, air conditioners, and factories. Daytime temperatures in cities are higher than in rural surroundings, and the nighttime temperature difference is even higher because of heat retained from the day. Cities are prone to heat waves, often associated with air pollution. Extreme heat and poor air quality both pose health risks to children, older people, those with chronic illnesses, and outdoor workers. High humidity is also a major contributor to high ambient temperature because water vapor prevents the human body from cooling effectively through sweat- 


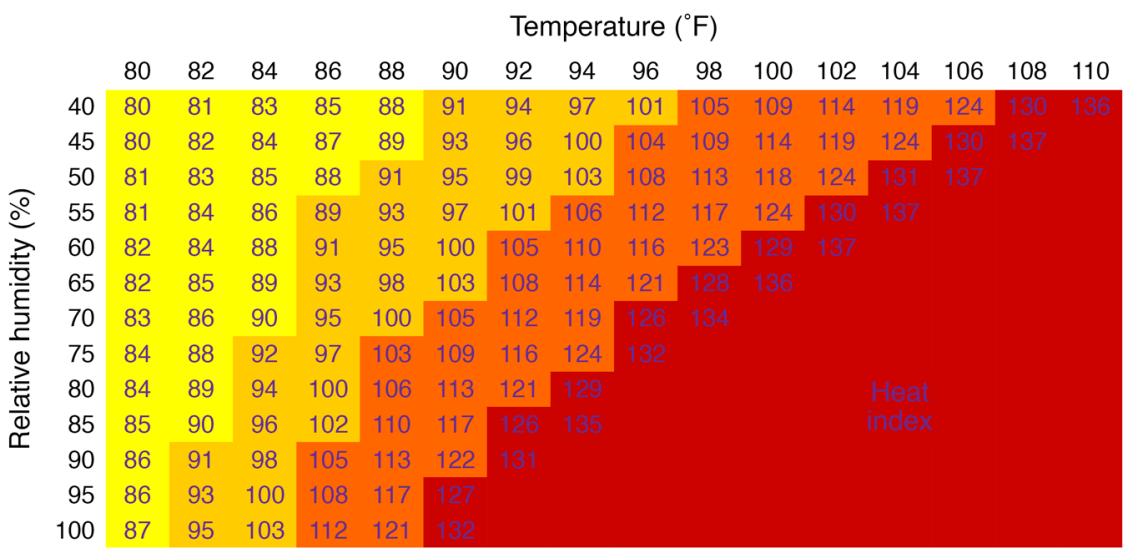

Likelihood of heat disorders with prolonged exposure or strenuous activity Caution

Extreme caution ing. The "heat index" indicates how hot it feels by factoring in effects of air temperature and humidity (Figure 1). For example, when the air temperature is $96^{\circ} \mathrm{F}$ and the humidity is $65 \%$, the heat index is $121^{\circ} \mathrm{F}$. Health warnings about extreme heat are based on the heat index exceeding $105^{\circ} \mathrm{F}-110^{\circ} \mathrm{F}$ for more than 2 consecutive days. Coastal communities are especially vulnerable to global warming, rising sea levels, and the combination of high temperature and humidity.

\section{Heat-related illnesses and mortality}

As heat waves become more common, more severe, and longer, we expect to see more heat-related illnesses and deaths, particularly in children, older people, those with chronic health conditions, and poor or underserved communities (6). Heat cramps are associated with painful muscle spasms in the abdomen, arms, or legs caused by water and salt depletion. Heat exhaustion is a more severe illness that occurs from prolonged exposure to extreme heat, is associated with dehydration, and requires emergency treatment. The symptoms of heat exhaustion are excessive sweating, fatigue, headache, dizziness, irritability, nausea and vomiting, thirst, and decreased urination. Heat stroke is the most serious heat-related illness, requiring emergency treatment (6). Heat stroke occurs when the body's thermoregulatory mechanisms fail and the core temperature rises to $41.1^{\circ} \mathrm{C}\left(106^{\circ} \mathrm{F}\right)$ or higher. Heat stroke may be preceded by heat cramps or heat exhaustion, but it can also happen suddenly. Excessive heat causes tissue injury, disrupts cellular processes, denatures proteins, and destabilizes cellular membranes. Above $49^{\circ} \mathrm{C}$, cells undergo rapid death from necrosis. Symptoms and signs of heat stroke include profuse sweating, hot and dry skin, nausea and vomiting, hypotension, intense headache, mental confusion, and loss of consciousness (6).

In the United States, extreme heat causes more deaths than other weatherrelated hazards, i.e., cold, hurricanes, tornadoes, or floods $(6,7)$. The annual heat-related death toll in the United States is approximately $1500(6,7)$. The July 1995 heat wave in Chicago claimed more than 700 lives (8). About 65,000 patients with acute heat-related illnesses are seen in the emergency room each summer in the United States (6). The August 2003 heat wave in Paris, France, killed nearly 15,000 people, mostly elderly and poor people $(9,10)$. Since 2015 , between 500 and 3500 excess deaths from extreme heat have been reported each summer in France (10). In a recent study, Guo et al. examined the heat-related mortality in 412 communities within 20 countries/ regions and projected excess mortality in relation to greenhouse gas emissions, future heat waves, and adaptation (11) Assuming communities do not adapt to future climate change, the heat-related excess mortality is expected to increase the most in tropical and subtropical countries/regions, while European countries and the United States will have smaller increases (11).
Figure 1. The National Weather Service heat index. The heat index is a measure of how hot it really feels when relative humidity is factored in to the actual air temperature. The red zone without numbers indicates extreme danger. Temperature ${ }^{\circ} \mathrm{F}=\left({ }^{\circ} \mathrm{C} \times 1.8\right)+32$. Source: National Oceanic and Atmospheric Administration, National Weather Service (15)

\section{What to do about global warming}

Global warming is a major threat to human existence. The solutions are likely to be complex and involve short-term strategies to adapt to the current temperatures, as well as long-term strategies to drastically reduce future emissions of greenhouse gases (12-14). Strategies for climate adaptation include better forest management, defenses against rising sea levels and flooding, improved infrastructure to withstand extreme weather events, and the development of comprehensive services to address food and water insecurity, health care, and economic needs of vulnerable populations. Future efforts to mitigate global warming would involve reducing the flow of heat-trapping greenhouse gases into the Earth's atmosphere by drastically curbing the burning of fossil fuels and developing effective technologies to capture and store greenhouse gases in forests, soil, oceans, or other sinks. Hopefully, these concerted efforts would allow the Earth enough time to recover and sustain the lives of humans and other species.

\section{Acknowledgment}

RSA is supported by a Bloomberg Distinguished Professorship.

Address correspondence to: Rexford S. Ahima, Division of Endocrinology, Diabetes and Metabolism, Department of Medicine, Johns Hopkins University School of Medicine, 1830 East Monument Street, Baltimore, Maryland 21287, USA. Phone: 410.550.7626; Email: ahima@jhmi.edu. 
1. NASA's Scientific Visualization Studio. Graphic: Global Warming from 1880 to 2018. http://climate.nasa.gov/climate_resources/139/ graphic-global-warming-from-1880-to-2018. Updated February 12, 2019. Accessed December 2, 2019.

2. Lindsay R, Dahlman L. Climate Change: Global Temperature. September 19, 2019. News \& Features. http://www.climate.gov/news-features/ understanding-climate/climate-change-globaltemperature. Accessed December 2, 2019.

3. United Nations. Greenhouse gas levels in atmosphere reach new record. November 22, 2018. http://www.un.org/sustainabledevelopment/ blog/2018/11/greenhouse-gas-levels-inatmosphere-reach-new-record. Accessed December 2, 2019.

4. Tansey EA, Johnson CD. Recent advances in thermoregulation. Adv Physiol Educ. 2015;39(3):139-148.

5. Berardelli J. Yale Climate Connections. Heat waves and climate change: Is there a connection? June 25, 2019. http://www.yaleclimateconnections. org/2019/06/heat-waves-and-climate-change-isthere-a-connection. Accessed December 2, 2019.
6. Centers for Disease Control and Prevention. Climate Change and Extreme Heat: What You Can Do to Prepare. http://www.cdc.gov/ climateandhealth/pubs/extreme-heat-guidebook. pdf. Accessed December 2, 2019.

7. Anderson GB, Oleson KW, Jones B, Peng RD. Projected trends in high-mortality heatwaves under different scenarios of climate, population, and adaptation in 82 US communities. Clim Change. 2018;146(3-4):455-470.

8. Holcombe M. A Heat Wave in Chicago 24 Years Ago Left More Than 700 Dead. The Mayor Says They've Learned Lessons since Then. CNN. July 20, 2019. http://www.cnn.com/2019/07/20/us/ chicago-heatwave-repeat-1995-wxc-trnd/index. html. Accessed December 2, 2019.

9. Tagliabue J. Heat Death Toll Forces a Shocked France to Question Itself. New York Times. August 20, 2003. http://www.nytimes. com/2003/08/20/international/europe/heatdeath-toll-forces-a-shocked-france-to-question. html. Accessed December 2, 2019.

10. Peltier E. As Extreme Heat Becomes New Normal in Europe, Governments Scramble to Respond. New York Times. July 26, 2019. http://www.nytimes.com/2019/07/26/world/ europe/france-europe-extreme-heat.html. Accessed December 2, 2019.

11. Guo Y, et al. Quantifying excess deaths related to heatwaves under climate change scenarios: A multicountry time series modelling study. PLoS Med.2018;15(7):e1002629.

12. United Nations. Sustainable Development Goals. Goal 13: Take urgent action to combat climate change and its impacts. http://www.un.org/ sustainabledevelopment/climate-change. Accessed December 2, 2019.

13. NASA. Responding to Climate Change. http:// climate.nasa.gov/solutions/adaptation-mitigation. Updated November 20, 2019. Accessed December 2, 2019.

14. United States Environmental Protection Agency. What EPA Is Doing about Climate Change. http://archive.epa.gov/epa/climatechange/ what-epa-doing-about-climate-change.html. Accessed December 2, 2019.

15. National Oceanic and Atmospheric Administration, National Weather Service. Heat Index. https://www.weather.gov/safety/heat-index. Accessed December 2, 2019. 